\title{
Kontrol Angle of Attack untuk Optimasi Daya pada Vertical Axis Wind Turbine Tipe Darrieus
}

\author{
WAHYU AULIA NURWICAKSANA, BUDHY SETIAWAN, IKA NOER \\ SYAMSIANA, SEPTYANA RISKITASARI
}

Teknik Elektro Politeknik Negeri Malang, Indonesia

Email: wahyu_aulia_nurwicaksana@polinema.ac.id

Received 3 Februari 2020 | Revised 23 Maret 2020 | Accepted 25 Juli 2020

\begin{abstract}
ABSTRAK
VAWT (Vertical Axis Wind Turbine) tipe Darrieus NACA0015 merupakan salah satu model dari turbin angin yang bekerja dengan menggunakan angin sebagai sumber penggerak. Namun dari hasil pengamatan, kecepatan angin yang ada tidak konstan setiap saat. Sehingga dari permasalahan ini perlu suatu kontrol yaitu dengan mengendalikan sudut kerja blade VAWT yang dikenal dengan kontrol angle of attack (AoA). Prinsip kerja kontrol AoA yaitu sudut blade diatur agar VAWT bekerja secara optimum dan dapat meningkatkan efisiensi. Metode kontrol AoA menggunakan PID (Proportional-Integral-Derivative) dengan memberikan nilai trial and error pada Kp, Ki, Kd. VAWT ini menggunakan konstanta TSR (Tip Speed Ratio) yaitu 4. Hasil dari penelitian ini yaitu daya yang dihasilkan VAWT dengan kontrol AoA mendapatkan rata-rata efisiensi sebesar 5.16\%, sedangkan VAWT tanpa kontrol mendapatkan efisiensi sebesar 3.49\%. Sehingga dapat disimpulkan bahwa dengan kontrol AoA, rata-rata efisiensi dayanya naik sebesar $1.67 \%$ dari yang tanpa kontrol.
\end{abstract}

Kata Kunci: Kontrol Angle of Attack (AOA), VAWT, TSR, Efisiensi

\begin{abstract}
VAWT (Vertical Axis Wind Turbine) type Darrieus NACA0015 is one model of a wind turbine that works by using wind as a source of propulsion. Conditions from observations, wind speeds that are not constant every time. So from this problem needs control VAWT by controlling the working angle of the VAWT blade is the angle of attack control (AoA). The principle AoA control is that the blade angle adjusted so that the VAWT works optimally and can improve the efficiency. AoA control method uses PID (Proportional-Integral-Derivative) by providing trial and error values for Kp, Ki, Kd. VAWT uses TSR (Tip Speed Ratio) constant which is 4. The results of this research, VAWT with AOA control get an average efficiency of $5.16 \%$, while without control gets an average efficiency of $3.49 \%$. So it can be concluded that with AoA control, the average power efficiency increases by $1.67 \%$ from those without control.
\end{abstract}

Keywords: Angle of Attack (AOA) Control, VAWT, TSR, Efficiency 


\section{PENDAHULUAN}

Energi angin merupakan salah satu sumber energi terbarukan yang berpotensi sebagai pembangkit energy listrik (Fachri \& Hendrayana, 2017) (Kholiq, 2015) (Sitorus, dkk, 2015) (Widyanto, dkk, 2018). Berdasarkan peta potensi energi angin yang dipublikasikan oleh World Bank Group, Departmen of Wind Energy, Vortex dan ESMAP, Indonesia merupakan wilayah potensial untuk mengembangkan Pembangkit Listrik Tenaga Angin dengan kondisi kecepatan angin yang berhembus antara $2 \mathrm{~m} / \mathrm{s}$ sampai $8 \mathrm{~m} / \mathrm{s}$ seperti yang ditunjukkan pada Gambar 1 (Atlas, 2017).

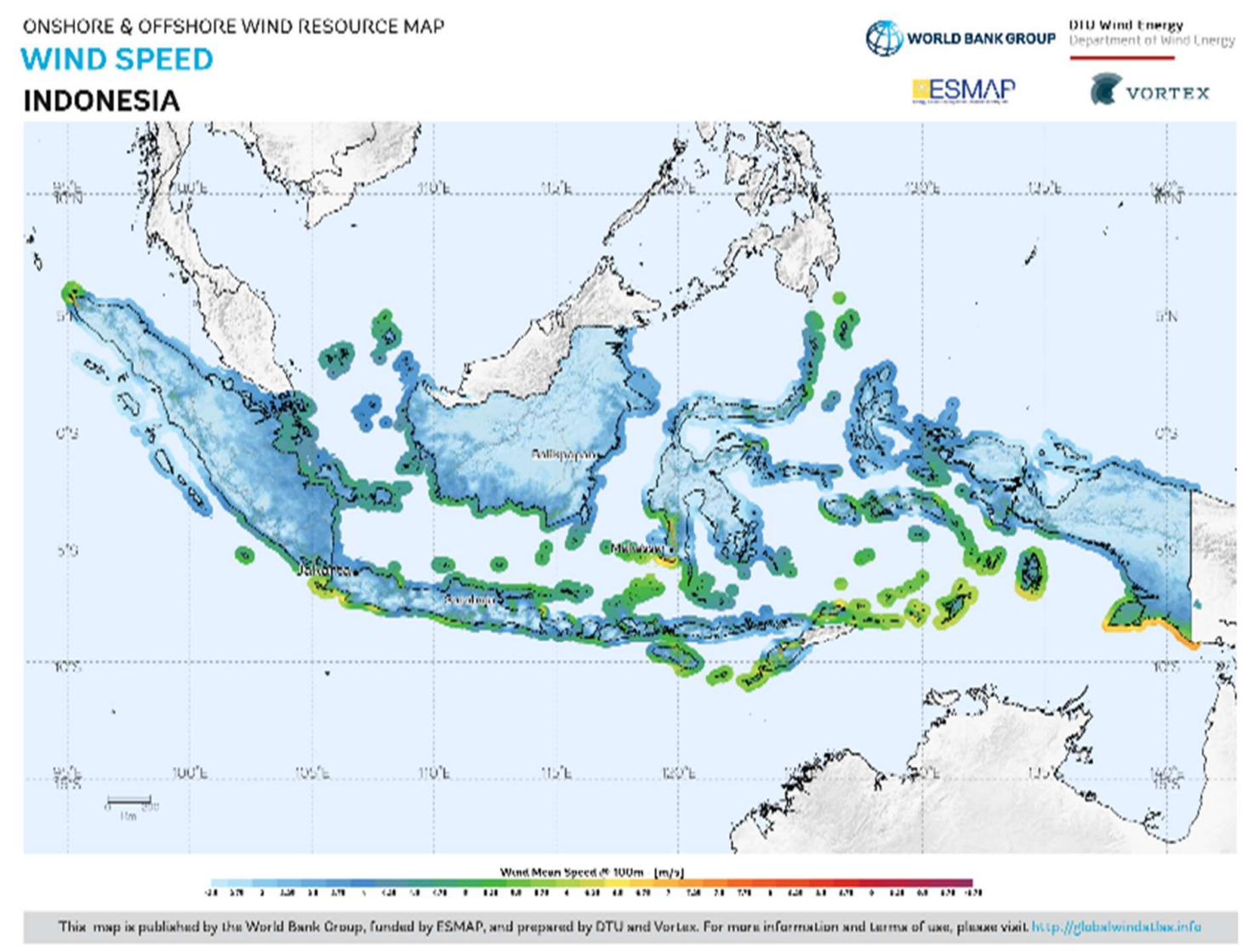

\section{Gambar 1. Peta Potensi Energi Angin Indonesia}

Sedangkan menurut pengelompokkan kecepatan angin berdasarkan Skala Beufort pada Tabel 1 , kecepatan angin di Indonesia tergolong pada jenis angin sepoi-sepoi hingga keras. Dimana Skala Beaufort merupakan skala yang sering digunakan untuk mengukur kecepatan angin yang dikelompokkan mulai dari $0 \mathrm{~m} / \mathrm{s}$ sampai $>29 \mathrm{~m} / \mathrm{s}$ yang berfungsi sebagai indikasi kondisi angin tenang hingga angin berbahaya. Berikut adalah skala Beaufort yang ditunjukkan pada Tabel 1 (Aji \& Cahyadi, 2015). 
Tabel 1. Skala Kecepatan Angin berdasarkan Skala Beufort

\begin{tabular}{|c|c|c|c|c|}
\hline \multirow{2}{*}{ No } & \multicolumn{2}{|c|}{ Kecepatan Angin } & \multirow{2}{*}{ Macam Angin } & \multirow{2}{*}{ Indikator di Daratan } \\
\hline & $(\mathrm{m} / \mathrm{s})$ & (km/jam) & & \\
\hline 1. & $0,0-0,5$ & $0-1$ & Reda & Tiang Asap Tegak \\
\hline 2. & $0,6-1,7$ & $2-6$ & Sepoi-sepoi & Tiang Asap Mirip \\
\hline 3. & $1,8-3,3$ & $7-12$ & Lemah & Daun Bergerak \\
\hline 4. & $3,4-5,2$ & $13-18$ & Sedang & Ranting Bergerak \\
\hline 5. & $5,3-7,4$ & $19-26$ & Agak Keras & Dahan Bergerak \\
\hline 6. & $7,5-9,8$ & $27-35$ & Keras & Batang Pohon Bergerak \\
\hline 7. & $9,9-12,4$ & $36-44$ & Sangat Keras & $\begin{array}{c}\text { Batang Pohon Besar } \\
\text { Bergerak }\end{array}$ \\
\hline 8. & $12,5-15,2$ & $45-54$ & Ribut & Pohon Kecil Patah \\
\hline 9. & $15,3-18,2$ & $55-65$ & Ribut Hebat & Pohon Besar Tumbang \\
\hline 10. & $18,3-21,5$ & $66-77$ & Badai & Rumah Roboh \\
\hline 11. & $25,2-29,0$ & $78-90$ & Badai Hebat & Benda Berat Bertebangan \\
\hline 12. & $>29,0$ & $>105$ & Taifun & $\begin{array}{c}\text { Benda Bertebangan Sejauh } \\
\text { Beberapa Kilometer }\end{array}$ \\
\hline
\end{tabular}

Mekanisme pemanfaatan energi angin adalah dengan menggunakan turbin angin dengan mengubah energi mekanik menjadi energi listrik (C.M.Vivek, dkk, 2017). Terdapat dua jenis turbin angin yang sering digunakan saat ini, yaitu Vertical Axis Wind Turbine dan Horizontal Axis Wind Turbine atau yang dikenal sebagai VAWT dan HAWT (Johari, dkk, 2018) (Wenehenubun, dkk, 2015). Berdasarkan penelitian sebelumnya, VAWT memiliki beberapa keunggulan dibandingkan HAWT, yaitu biaya produksi yang lebih rendah, pemasangan dan perawatan yang mudah, dapat menyerap energi angin dari segala arah, dan memiliki kecepatan rotasi yang relatif rendah sehingga menghasilkan kebisingan yang rendah (Jin, dkk, 2015).

Namun ketika membahas mengenai energi angin, kondisi yang perlu diperhatikan adalah karakteristik kecepatan angin di Indonesia yang sering berubah-ubah atau tidak stabil sehingga menyebabkan daya yang dihasilkan dari turbin angin tidak konstan (Pahlevi, dkk, 2016). Oleh karena itu perlu dibuat desain mekanis dan kontrol elektronik dari turbin angin menggunakan turbin angin sumbu vertical tipe Darrieus dengan NACA 0015. Sistem kontrol yang digunakan untuk mengoptimalkan kerja dari turbin angin yaitu dengan memberikan kontrol pada sudut kerja dan posisi sudut blade atau yang dikenal dengan angle of attack control. Turbin angin yang dilengkapi dengan angle of attack control, dapat mengubah sudut kerja blade untuk bergerak menutup mendekati sumbu poros atau membuka menjauhi poros. Angle of attack control ini bekerja pada saat kecepatan angin dengan kategori pelan maka blade akan bergerak menyesuaikan sudutnya sehingga energi yang dihasilkan turbin angin tetap mencapai optimum. Sedangkan saat angin berhembus kencang maka blade diatur posisinya sehingga kecepatan dari turbin angin bertahan pada kecepatan yang telah ditentukan. Dari angle of attack contro/ perubahan aerodinamis yang terjadi di turbin angin merubah daya angin yang ditangkap sehingga mengakibatkan kecepatan putaran dari turbin angin juga akan berubah (Elkhoury, dkk, 2015).

Tujuan dari penelitian menggunakan kontrol angle of attack adalah meningkatan daya tangkapan dari turbin angin yang akan meningkatkan efisiensi dari turbin angin. Pemanfaatan kontrol sudut blade turbin angin juga diharapkan dapat mengurangi daya tangkapan turbin angin yang dapat menyebabkan kerusakan perangkat mekanik dan elektronik ketika mendapatkan tangkapan angin yang berlebih. 
Dari beberapa penelitian sebelumnya yang telah dilakukan mengenai pengontrolan angle of attack turbin angin hanya sebatas pada pembuatan simulasi kontrol sudut blademenggunakan Simulink pada matlab ataupun software-software pemodelan lainnya, yaitu membahas mengenai efek perubahan angle of attack turbin angin tipe horizontal maupun vertikal (Djalal, dkk, 2017) (Ma, dkk, 2016) (Pahlevi, dkk, 2016) (Zhao, dkk, 2018). Berdasarkan hasil simulasi pengontrolan angle of attack tersebut, dapat diamati data mengenai RPM, Daya, dan efisiensi turbin angin. Sedangkan pada penelitian ini dilakukan mengembangan sistem kontrol yang mencakup kontrol mekanik dan elektronik yang akan diterapkan pada turbin angin dengan tipe VAWT (Vertical Axis Wind Turbine) tipe Darrieus menggunakan NACA0015. Selain itu dilengkapi dengan kontrol PID yang berfungsi untuk mengontrol besar sudut motor servo yang berpengaruh terhadap besar angle of attack dari masing-masing blade turbin angin.

\section{METODE}

\subsection{Parameter-Parameter Turbin Angin}

\section{Energi Angin}

Daya yang dihasilkan oleh angin dapat dihitung seperti yang ditunjukkan pada Persamaan (1) (Gulve \& Barve, 2014) :

$$
P=\frac{1}{2} \times \rho \times A \times V^{3}
$$

Dimana :

$\mathrm{P}=$ energi angin (Watt)

$A=$ area tangkapan angin $\left(\mathrm{m}^{2}\right)$

$\rho=$ konstanta massa jenis yang ada di udara $\left(1.225 \mathrm{~kg} / \mathrm{m}^{3}\right)$

$\mathrm{V}=$ kecepatan angin $(\mathrm{m} / \mathrm{s})$

Persamaan (1) merupakan Persamaan untuk energi angin secara umum, Namun daya angin yang diterima oleh turbin angin tidak dapat diterima 100\%. Sehingga dari Persamaan (1) dapat dibuat Persamaan untuk turbin angin dengan menggunakan Persamaan (2):

$$
P_{t}=\frac{1}{2} \times \rho \times A \times V^{3} \times C_{p} \times N_{g} \times N_{b}
$$

Dimana:

$P_{t} \quad=$ Daya mekanik turbin angin

$\mathrm{C}_{\mathrm{p}}=$ Koefisien kerja turbin angin (koefisien maksimum menurut teori Betz Limit=0,59, Koefisien maksimum berdasarkan desain yang dibuat $=0,35$ )

$\mathrm{N}_{\mathrm{g}}$ = Efisiensi dari generator (tergantung dari generator yang digunakan)

$\mathrm{N}_{\mathrm{b}}$ = efisiensi dari gearbox (maksimal jika tidak ada celah dapat mencapai 80\%)

\section{Daya Turbin Angin (Generator)}

Daya turbin angin sendiri merupakan daya yang dihasilkan generator yang digerakkan oleh turbin angin dengan menggunakan Persamaan (3) (Gulve \& Barve, 2014) :

$$
P_{t}=\text { Tegangan } \times \text { Arus }
$$

Di mana, Pt adalah Turbine Power (Watts), Tegangan yang dihasilkan dalam volt, dan Arus dalam ampere. 


\section{Efisiensi}

Dalam teori Betz, koefisien daya selalu lebih besar dari 16/27 (0,59) (Korprasertsak \& Leephakpreeda, 2016). Karakteristik ini dapat digunakan sebagai perhitungan efisiensi dari VAWT. Koefisien nilai sebagai (Karan, dkk, 2018) :

$$
C p=\frac{P t}{P} \times 100 \%
$$

Di mana Cp adalah Efisiensi Daya (\%).

\section{Tip Speed Ratio ( $\lambda$ )}

Tip Speed Ratio adalah perbandingan kecepatan putaran dari turbin angin dan radius turbin angin terhadap kecepatan angin, dirumuskan dalam Persamaan (5) (Karan, dkk, 2018) (Rezaeiha, dkk, 2017) :

$$
\lambda=\frac{\omega \times r}{V}
$$

Dimana, $r$ adalah jari-jari turbin angin $(m)$, dan Kecepatan sudut diperoleh dari:

$$
\omega=\frac{2 \times \pi \times R P M}{60}
$$

Sehingga dari rumus tersebut diperoleh Persamaan sebagai berikut:

$$
\lambda=\frac{2 \times \pi \times R P M \times r}{60 \times V}
$$

\subsection{Desain dan Perancangan Elektronik}

\section{Metode Desain Elektronik}

Diagram blok merupakan bagian-bagian pernyusun sebuah sistem yang meliputi input, pemrosesan, dan output. Berikut adalah blok dari sistem yang dibuat, yaitu:

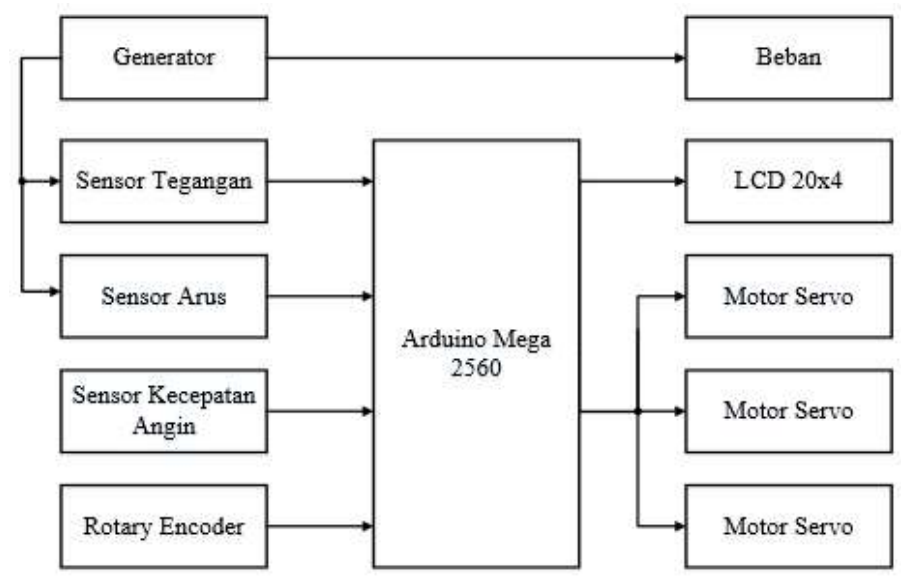

Gambar 2. Blok Diagram Elektronik

Desain elektronik turbin angin yang dibuat terdiri dari beberapa komponen penyusun seperti yang ditampilkan pada diagram blok pada Gambar 2. Pada bagian input terdiri dari sensor tegangan, arus, kecepatan angin, rotary encoder. Dari berbagai sensor tersebut akan dilakukan pemrosesan data yang akan dikeluarkan pada output. Output pada sistem terdiri dari tiga motor servo dan satu LCD 20x4 yang berfungsi untuk menampilkan hasil pembacaan 
data dari sistem. Prosessor yang digunakan untuk pemrosesan data menggunakan Arduino Mega 2560.

\subsection{Desain dan Perancangan Software}
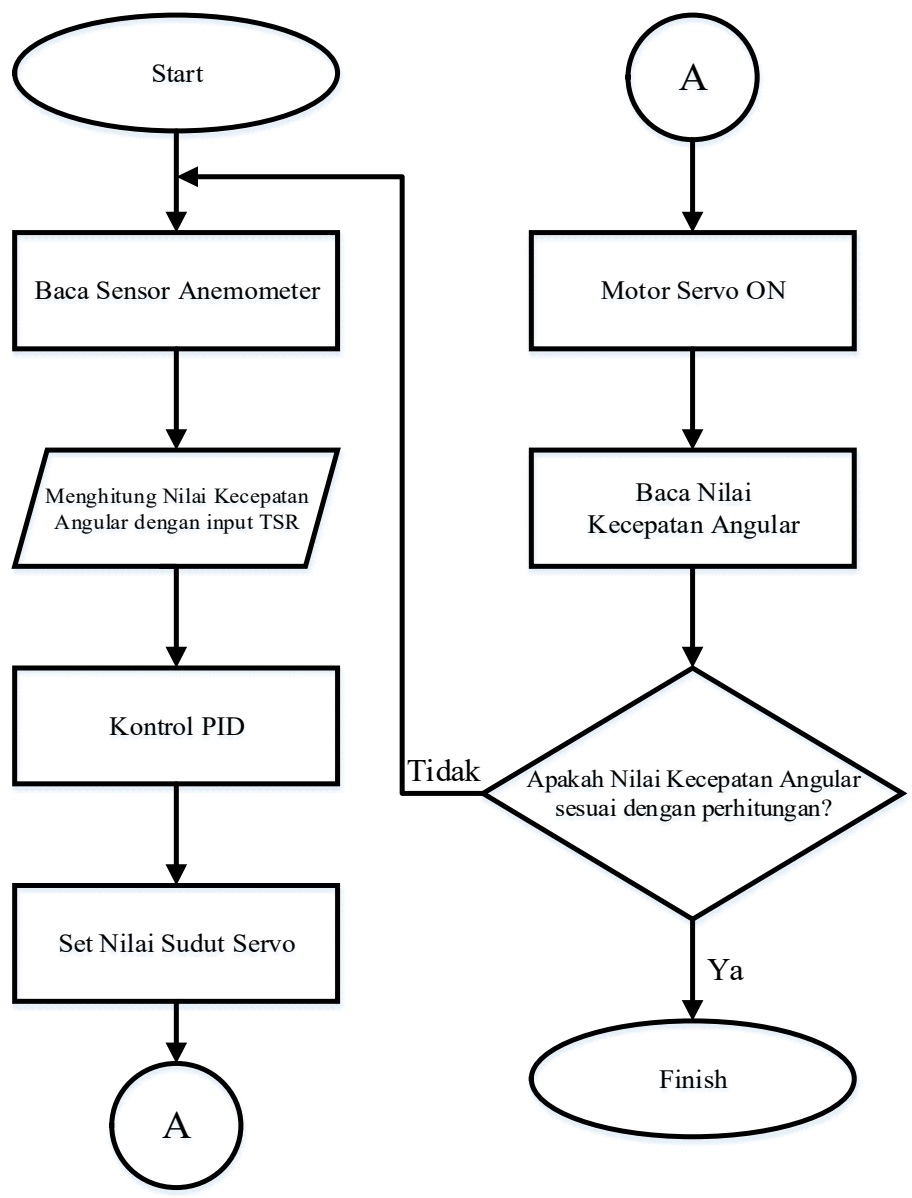

Gambar 6. Flowchart Sitem Kontrol

Input pertama adalah dari data kecepatan angin yang diperoleh dari sensor anemometer. Setelah itu data kecepatan angin digunakan untuk menghitung nilai kecepatan angular dengan input nilai TSR sebagai setpoint. Data setpoint akan dikontrol oleh PID untuk mengaktifkan 3 motor servo yang terhubung ke blade untuk mengatur sudut blade. Setelah perubahan sudut blade, nilai kecepatan putaran akan dibaca oleh sensor rotary encoder untuk sebagai umpan balik dari rumus kecepatan angular, apakah nilai kecepatan angular sudah sesuai atau tidak. Jika tidak, kontrol akan diulangi lagi hingga nilai kecepatan angular dari pembacaan sensor sama dengan hasil perhitungan di setpoint.

\subsection{Desain dan Perancangan Kontrol Angle of Attack}

\section{Mekanisme Angle of Attack}

Mekanisme Angle of Attack pada VAWT yaitu dalam bentuk gerakan blade dan perubahan sudut blade untuk meningkatkan kinerja turbin (Hantoro, dkk, 2011). Angle of attack pada penelitian ini menggunakan motor servo untuk menggerakkan blade. Pemilihan motor servo dilakukan karena kemudahan dalam pengaturan sudutnya. 
Pada penelitian ini sistem sudut dari angle of attack yaitu jika posisi blade tegak lurus dengan poros jika dilihat dari atas maka sudutnya adalah 0 . Jika blade bergerak keluar menjauhi poros maka sudutnya positif, dan sebaliknya jika blade bergerak ke dalam mendekati poros maka sudutnya negatif. Gambar 3 menjelaskan sistem dari angle of attack.

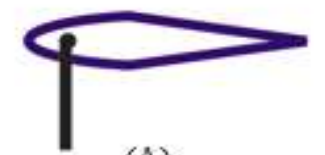

(A)

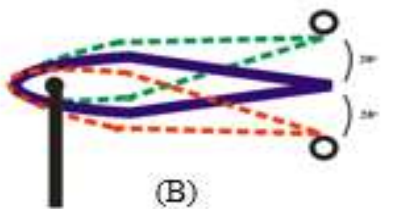

(B)

\section{Gambar 3. (A) Mekanisme Sudut Tetap, (B) Mekanisme Angle Of Attack}

Sistem dari Angle of attack contro/ ini mengacu pada nilai dari TSR seperti yang ditunjukkan pada Gambar 4 yang menujukkan perbandingan grafik antara koefisien daya terhadap TSR dengan berbagai tipe dari turbin angin (Aryanto, dkk, 2013).

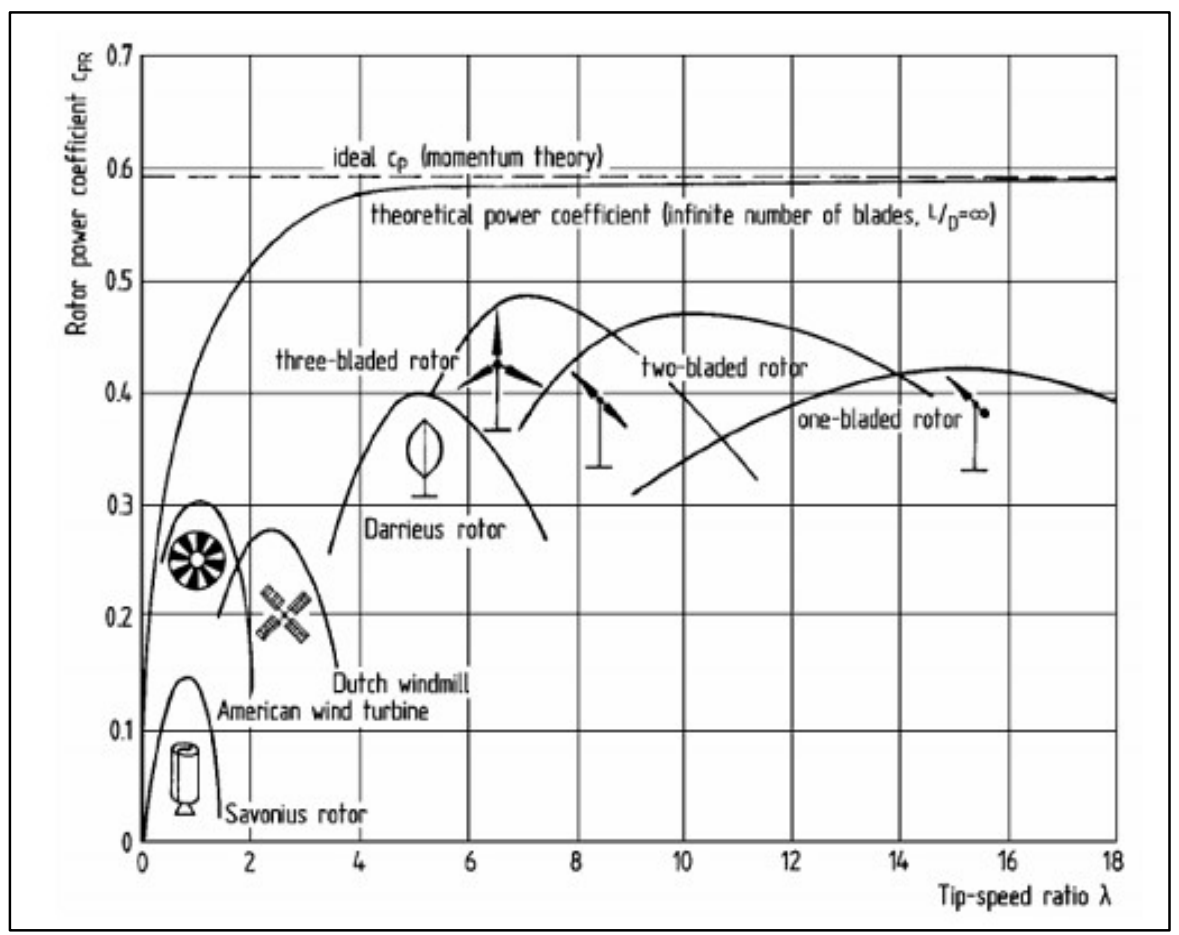

Gambar 4. Grafik Perbandingan Koefisien Daya dan TSR

\section{Desain Kontrol PID}

Pada tahap ini dilakukan perancangan desain kontrol PID untuk pengontrolan sudu blade turbin angin tipe vertical atau yang lebih dikenal dengan angle of attack. Pengimplementasian kontrol PID berfungsi untuk meningkatkan efisiensi dari daya listrik yang dihasilkan dari turbin angin. Gambar 5 merupakan diagram blok kontrol PID dari sistem yang dibuat. 


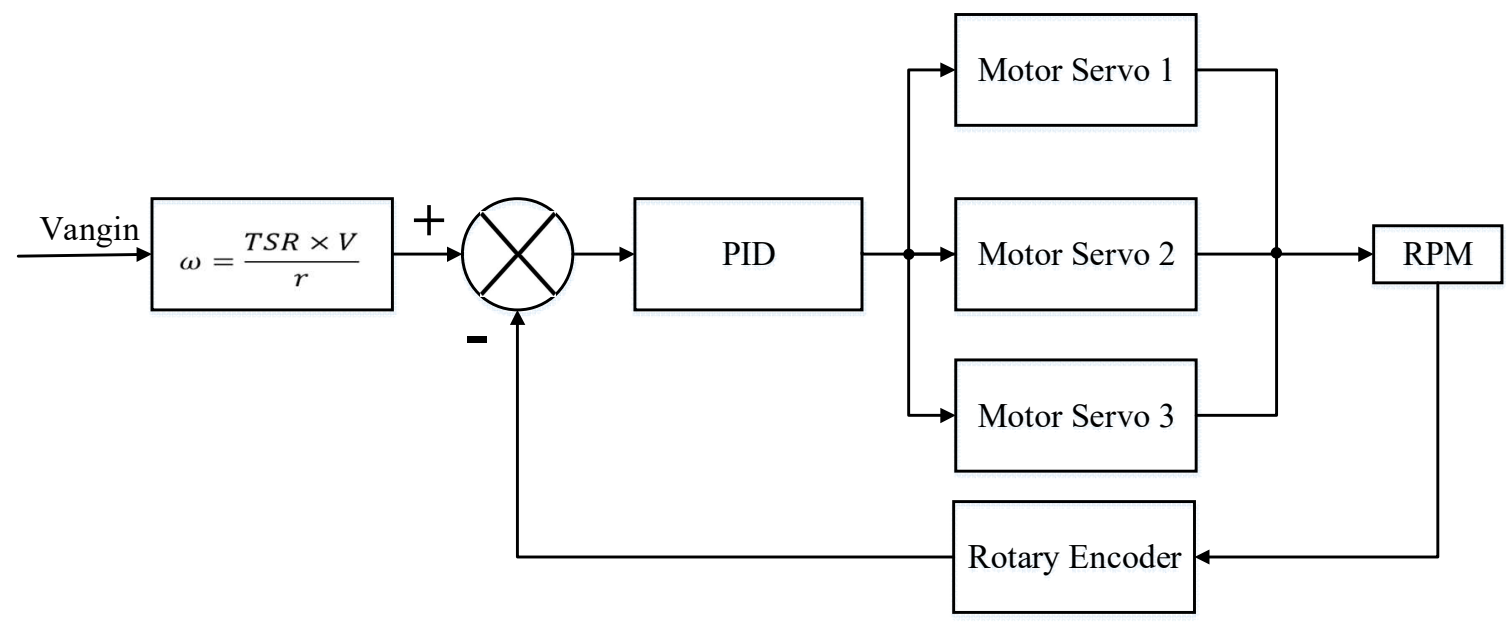

Gambar 5. Metode Kontrol PID

Ketika sistem diaktifkan, tahap pertama adalah membaca nilai input berupa kecepatan angin yang didapatkan dari hasil pembacaan sensor anemometer, kemudian dilakukan perhitungan sehingga menghasilkan nilai TSR ( Tip Speed Ratio) yang dijadikan setpoint sistem. Setelah itu, kontrol PID berfungsi untuk mengatur nilai ketiga sudut motor servo MG55 agar mampu mempertahankan nilai TSR sesuai dengan setpoint. Hasil pembacaan nilai TSR secara realtime didapatkan dari pembacaan nilai kecepatan putaran turbin angin yang dibaca oleh sensor rotary endcoder, yang kemudian dikonversi kedalam rumus TSR sebagai umpan balik sistem.

\subsection{Spesifikasi Alat Keseluruhan}

Pembuatan alat pada penelitian ini meliputi pembuatan mekanik alat secara real dengan spesifikasi alat sebagai berikut:

\section{Spesifikasi Elektronik}

1. Sensor

- Sensor Tegangan DC

- INA219 (Sensor Arus)

- Rotary Endcoder (Sensor RPM)

- Anemometer Cup (Sensor Kecepatan Angin)

2. Processor

: Arduino Mega 2560

3. Tampilan

: LCD 20x4

\section{Spesifikasi Mekanik}

Jenis Turbin Angin

Diameter

Tinggi Maksimum

Material Blade

Material Pemegang Blade

Material AS

Generator

- Jenis Generator
: VAWT tipe Darrieus

: $90 \mathrm{~cm}$

: $200 \mathrm{~cm}$

: Kayu Balsa

: Pipa dan Alumunium Dural

: Stainless steel

: Permanent Magnet Synchronous Generator (PMSG) 


\section{HASIL DAN PEMBAHASAN}

\subsection{Parameter Pengujian}

Pengujian sistem dilakukan dengan cara mengamati beberapa parameter pengujian, antara lain:

1. Perubahan nilai TSR berdasarkan hasil perubahan kecepatan angin disekitar turbin angin.

2. Perubahan nilai sudut motor servo berdasarkan perubahan nilai kecepatan putaran turbin angin yang dihasilkan

3. Daya yang dihasilkan turbin angin terhadap perubahan kecepatan angin saat RPM turbin angin terkontrol maupun tidak terkontrol

\subsection{Metode Pengujian}

Berikut metode pengujian alat pada penelitian ini meliputi:

1. Ketika sistem diaktifkan, maka sistem akan membaca nilai kecepatan angin melalui sensor anemometer, melakukan pengukuran nilai TSR dari hasil pembacaan kecepatan angin, Dari hasil pembacaan nilai kecepatan angin disekitas turbin angin, akan dikonversikan kedalam nilai

2. Pengujian rotary endcoder dilakukan dengan cara memberikan kecepatan angin yang berubah-ubah pada turbin angin, sehingga menghasilkan perubahan kecepatan putaran turbin angin yang berubah-ubah pula.

3. Pengujian sistem kontrol dilakukan dengan cara memberikan kecepatan angin yang berubah-ubah pada turbin angin, ketika terdapat perubahan kecepatan angin maka kontrol PID akan berfungsi untuk mempertahankan posisi sudut blade untuk mempetahankan nilai daya listrik yang dihasilkan agar maksimal.

4. Sistem akan terus melakukan pembacaan data secara real time dari masing-masing sensor yang terhubung hingga sistem dimatikan.

\subsection{Data Pengujian Kecepatan Putaran VAWT}

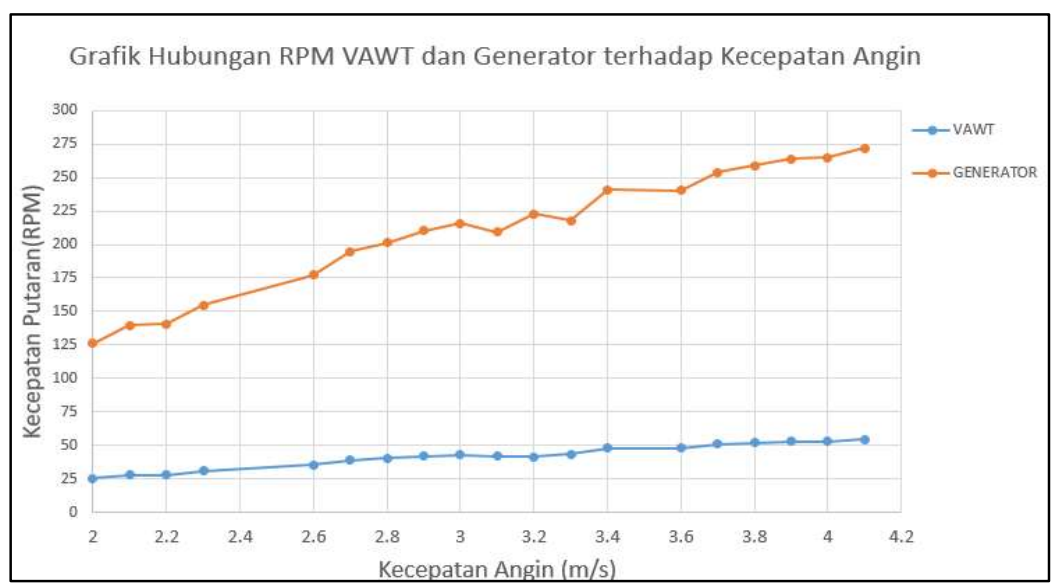

Gambar 8. Grafik Hubungan RPM VAWT dan Generator terhadap Kecepatan Angin

Gambar 8 merupakan rata-rata dari nilai kecepatan putaran VAWT, dijelaskan bahwa perbandingan RPM VAWT dan RPM generator adalah 1:5 dikarenakan penggunaan gearbox pada VAWT dan generator dengan perbandingan tersebut. Sehingga nilai dari pembacaan sensor pada VAWT dikalikan 5 untuk memperoleh RPM dari generator. Dari Grafik Gambar 8 dapat dilihat perbandingan RPM generator dan RPM VAWT terhadap kecepatan angin berbanding lurus. 


\subsection{Data Pengujian RPM Generator dengan Kontrol dan Tanpa Kontrol Angle of Attack Terhadap Kecepatan Angin}

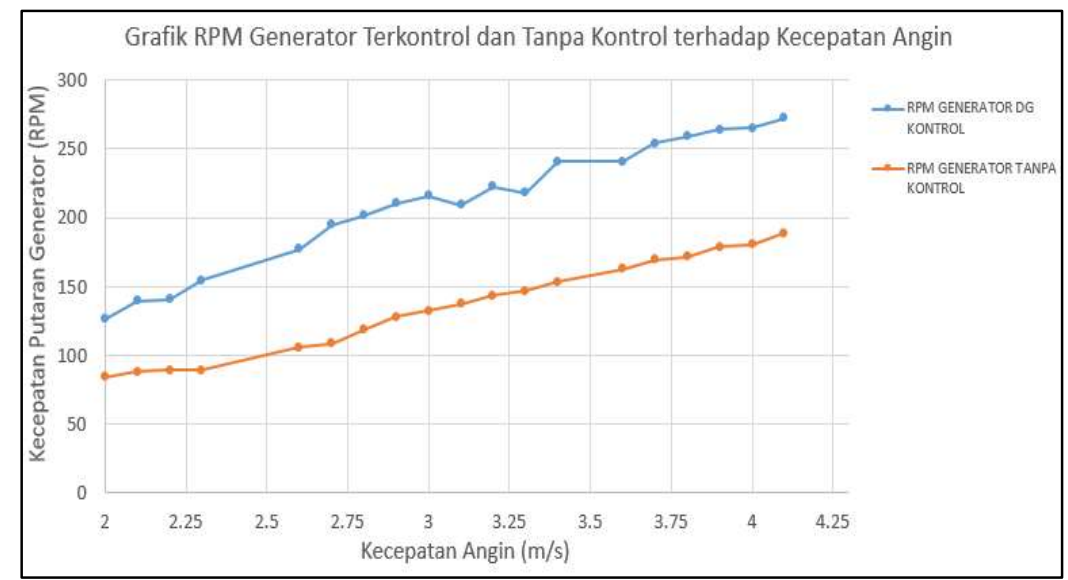

Gambar 9. Grafik RPM Generator dengan Kontrol dan Tanpa Kontrol Angle of Attack terhadap Kecepatan Angin

Grafik Gambar 9 merupakan rata-rata dari hasil pembacaan RPM generator dengan kontrol angle of attack dan tanpa kontrol angle of attack terhadap kecepatan angin. Pembacaan RPM tanpa kontrol dapat dikatakan linier dikarenakan tidak ada perubahan sudut dari blade yang berpengaruh terhadap kecepatan putaran. Namun TSR akan berubah-ubah tidak sesuai dengan yang diinginkan. Sedangkan pada RPM dengan kontrol terdapat beberapa perubahan nilai dikarenakan ada perubahan nilai sudut blade yang dapat menyebabkan perubahan nilai pembacaan RPM sebagai salah satu variable yang berpengaruh pada nilai TSR.

\subsection{Data Pengujian Daya Generator dengan Kontrol dan Tanpa Kontrol}

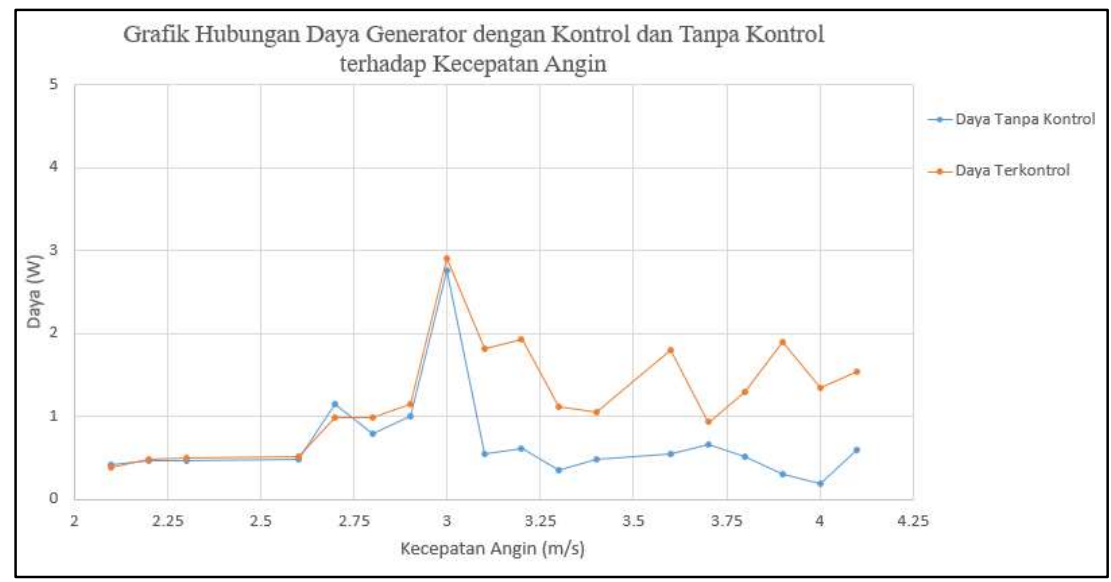

Gambar 11. Grafik Daya Generator dengan Kontrol dan Tanpa Kontrol Angle of Attack terhadap Kecepatan Angin

Gambar 11 metunjukkan grafik rata-rata dari daya generator yang terkontrol dan yang tanpa kontrol terhadap kecepatan angin. Dari Gambar 11 dapat dilihat bahwa daya yang dihasilkan generator dengan kontrol angle of attack lebih besar daripada yang tanpa kontrol. Daya yang dihasilkan generator dengan kontrol yaitu antara $0.39 \mathrm{~W}$ sampai $2.89 \mathrm{~W}$, sedangkan pada daya generator tanpa kontrol yaitu antara $0.19 \mathrm{~W}$ sampai $2.75 \mathrm{~W}$. Sehingga berdasarkan rata-rata 
dari seluruh data daya yang dihasillkan menggunakan kontrol adalah $1.26 \mathrm{~W}$, sedangkan yang tanpa kontrol yaitu $0.68 \mathrm{~W}$.

\subsection{Data Pengujian Efisiensi Daya dengan Kontrol dan Tanpa Kontrol}

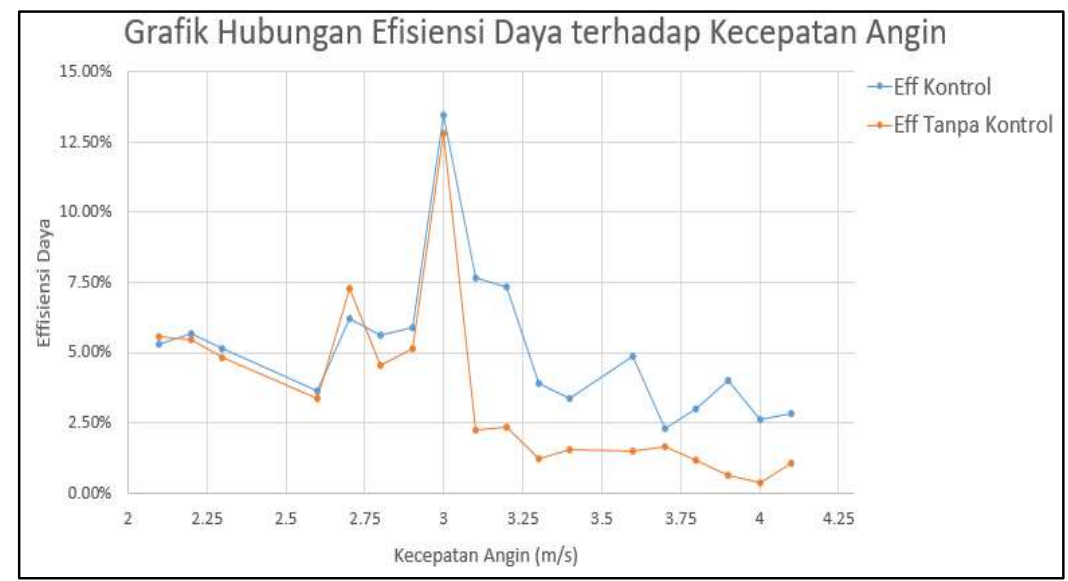

\section{Gambar 12. Grafik Efisiensi Daya dengan Kontrol dan Tanpa Kontrol Angle of Attack terhadap Kecepatan Angin}

Gambar 12 merupakan data dari efisiensi daya yang tanpa kontrol dan yang dengan kontrol terhadap kecepatan angin. Dari hasil Gambar 12 rata-rata efisiensi dari daya yang dikontrol lebih besar daripada daya yang tanpa kontrol. Dari data tersebut rata-rata efisiensi daya yang dengan kontrol yaitu $5.16 \%$. Sedangkan rata-rata efisiensi yang tanpa kontrol yaitu $3.49 \%$. Sehingga dapat dikatakan bahwa dengan kontrol angle of attack kenaikan rata-rata efisiensi daya yang dihasilkan dari VAWT pada penelitian ini adalah $1.67 \%$.

\subsection{Data Selisih Efisiensi Daya dengan Kontrol dan Tanpa Kontrol}

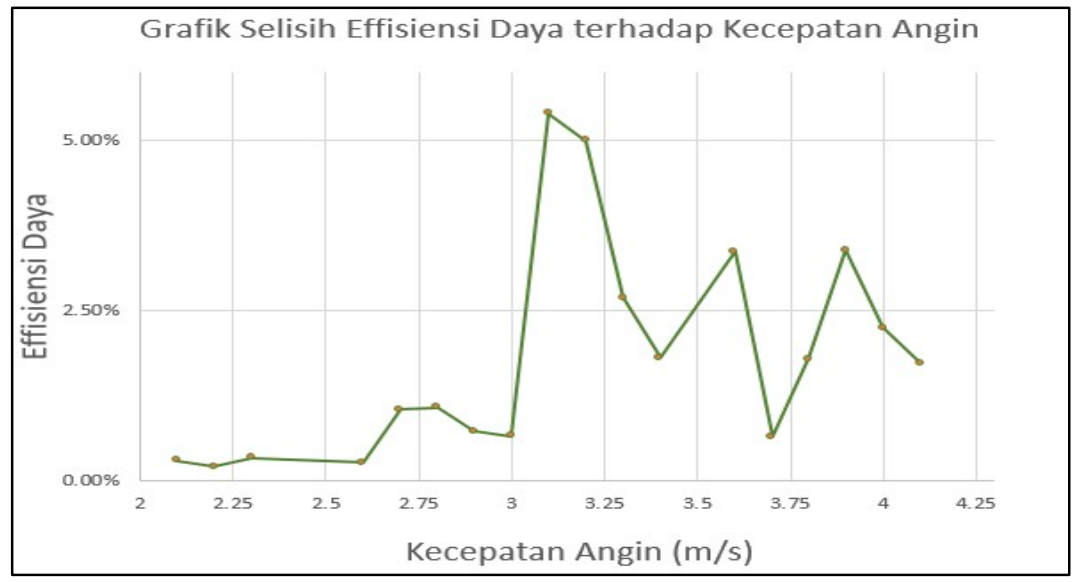

\section{Gambar 13. Grafik Selisih Efisiensi Daya dengan Kontrol dan Tanpa Kontrol terhadap} Kecepatan Angin

Grafik Gambar 13 merupakan data perubahan selisih efisiensi dari daya yang menggunakan kontrol dan yang tanpa kontrol angle of attack. Dari hasil grafik tersebut dapat dilihat bahwa selisih efisinesi maksimal yaitu $5.4 \%$ dan yang terkecil yaitu $0.21 \%$. Sedangkan rata-rata selisih efisiensi ini yaitu $1.67 \%$. Sehingga kontrol angle of attack dapat meningkatkan efisiensi daya yang dihasikan. 


\section{KESIMPULAN}

Kesimpulan dari penelitian ini adalah kontrol angle of attack dapat bekerja untuk mempertahankan setpoint yang diberikan yaitu 4 dengan kontrol sudut blade yang berubahubah tergantung hasil dari pembacaan kecepatan angin dan RPM. Dari hasil pengujian diperoleh rata-rata efisiensi daya tanpa kontrol angle of attack yaitu 3.49\%, sedangkan ratarata efisiensi dengan kontrol angle of attack lebih besar yaitu 5.16\%. Sehingga kenaikan efisiensi daya dari yang tanpa kontrol dengan yang menggunakan kontrol yaitu $1.67 \%$. Dari hasil penelitian ini diharapkan kedepannya dapat disempurnakan guna untuk pembuatan sistem yang lebih baik dengan memeperbaiki faktor mekanik, elektronik, dan generator.

\section{UCAPAN TERIMA KASIH}

Ucapan terimakasih diberikan kepada Kemenristekdikti yang sudah mendanai penelitian Tesis Magister, Skema Penelitian Pascasarjana (PPS) dengan nomor kontrak : 145/ SP2H/ LT/ DRPM/ IV/ 2019 tanggan 11 Maret 2019.

\section{DAFTAR RUJUKAN}

Aji, D. R., \& Cahyadi, M. N. (2015). Analisa Karakteristik Kecepatan Angin dan Tinggi Gelombang Menggunakan Data Satelit Altimetri (Studi Kasus: Laut Jawa). GEOID, 11(1), $75-78$.

Aryanto, F., Mara, M., \& Nuarsa, M. (2013). Pengaruh Kecepatan Angin Dan Variasi Jumlah Sudu Terhadap Unjuk Kerja Turbin Angin Poros Horizontal. Dinamika Teknik Mesin, 3(1), $50-59$.

Atlas, G. W. (2017). Wind Speed Layer. Retrieved from https://globalwindatlas.info.

C.M.Vivek, P. Gopikrishnan, R. Murugesh, \& Mohamed, R. R. (2017). a Review on Vertical and Horizontal Axis Wind Turbine. International Research Journal of Engineering and Technology, 4(4), 247-250.

Djalal, M. R., Imran, A., \& Setiadi, H. (2017). Desain Sistem Kontrol Pitch Angle Wind Turbine Horizontal Axis Menggunakan Firefly Algorithm. Jurnal Teknik Elektro, 9(1), 1-6.

Elkhoury, M., Kiwata, T., \& Aoun, E. (2015). Experimental and Numerical Investigation of a Three-Dimensional Vertical-Axis Wind Turbine with Variable-Pitch. Journal of Wind Engineering and Industrial Aerodynamics, 139, 111-123.

Fachri, M. R., \& Hendrayana, H. (2017). Analisa Potensi Energi Angin dengan Distribusi Weibull Untuk Pembangkit Listrik Tenaga Bayu (PLTB) Banda Aceh. CIRCUIT: Jurnal IImiah Pendidikan Teknik Elektro, 1(1), 1-8.

Gulve, P., \& Barve, S. B. (2014). Design and Construction Of Vertical Axis Wind Turbine. International Journal of Mechanical Engineering and Technology (IJMET), 5(10), 148155. 
Hantoro, R., Utama, I. K. A. P., Erwandi, \& Sulisetyono, A. (2011). An Experimental Investigation of Passive Variable-Pitch Vertical-Axis Ocean Current Turbine. ITB Journal of Engineering Science, 43(1), 27-40.

Jin, X., Zhao, G., Gao, K., \& Ju, W. (2015). Darrieus Vertical Axis Wind Turbine: Basic Research Methods. Renewable and Sustainable Energy Reviews, 42, 212-225.

Johari, M. K., Jalil, M. A. A., \& Shariff, M. F. M. (2018). Comparison of Horizontal Axis Wind Turbine (HAWT) and Vertical Axis Wind Turbine (VAWT). International Journal of Engineering and Technology(UAE), 74$), 74-80$.

Karan, S., Arpit, Y., Yuvraj, Z., Siddharth, P., \& Dharmendra Sapariya, P. (2018). Design, Analysis and Fabrication of Vertical Axis Wind Turbine. IJSRD-International Journal for Scientific Research \& Development, 6(03), 91-93.

Kholiq, I. (2015). Pemanfaatan Energi Alternatif Sebagai Energi Terbarukan untuk Mendukung Subtitusi BBM. Jurnal Iptek, 19(2), 75-91.

Korprasertsak, N., \& Leephakpreeda, T. (2016). Analysis and Optimal Design of Wind Boosters for Vertical Axis Wind Turbines at Low Wind Speed. Journal of Wind Engineering and Industrial Aerodynamics, 159, 9-18.

Ma, J., Koutsougeras, C., \& Luo, H. (2016). Efficiency of a Vertical Axis Wind Turbine ( VAWT ) with Airfoil Pitch Control. International COMSOL 2016 Conference, Boston, 1-7.

Pahlevi, E. L., Turbine, W., \& Coefficient, P. (2016). Pengaturan Pitch Angle Turbin Angin Berbasis Kendali Logika Fuzzy (Aplikasi Pada Data Angin Daerah Medan Tuntungan dan sekitarnya). Jurnal Singuda Ensikom, 14(40), 89-94.

Rezaeiha, A., Kalkman, I., \& Blocken, B. (2017). Effect of Pitch Angle on Power Performance and Aerodynamics of a vertical Axis Wind Turbine. Applied Energy, 197, 132-150.

Sitorus, B. D. P., Santoso, A. W. B., \& Rindo, G. (2015). Analisa Teknis Dan Ekonomis Penggunaan Wind Turbine. Jurnal Teknik Perkapalan, 3(1), 55-62.

Wenehenubun, F., Saputra, A., \& Sutanto, H. (2015). An Experimental Study on the Performance of Savonius Wind Turbines Related with the Number of Blades. Energy Procedia, 68, 297-304.

Widyanto, S., Wisnugroho, S., \& Agus, M. (2018). Pemanfaatan Tenaga Angin Sebagai Pelapis Energi Surya pada Pembangkit Listrik Tenaga Hibrid di Pulau Wangi-Wangi. Seminar Nasional Sains Dan Teknologi 2018, 1-12.

Zhao, Z., Wang, R., Shen, W., Wang, T., Xu, B., Zheng, Y., \& Qian, S. (2018). Variable Pitch Approach for Performance Improving of Straight-Bladed VAWT at Rated Tip Speed Ratio. Applied Sciences (Switzerland), 8(6), 1-23. 